\title{
Variation on Atmospheric Transmittance Solar Radiation at Kathmandu Valley
}

\author{
P. M. Shrestha, N. P. Chapagain, I. B. Karki and \\ K. N. Poudyal
}

Journal of Nepal Physical Society

Volume 6, Issue 1, June 2020

ISSN: 2392-473X (Print), 2738-9537 (Online)

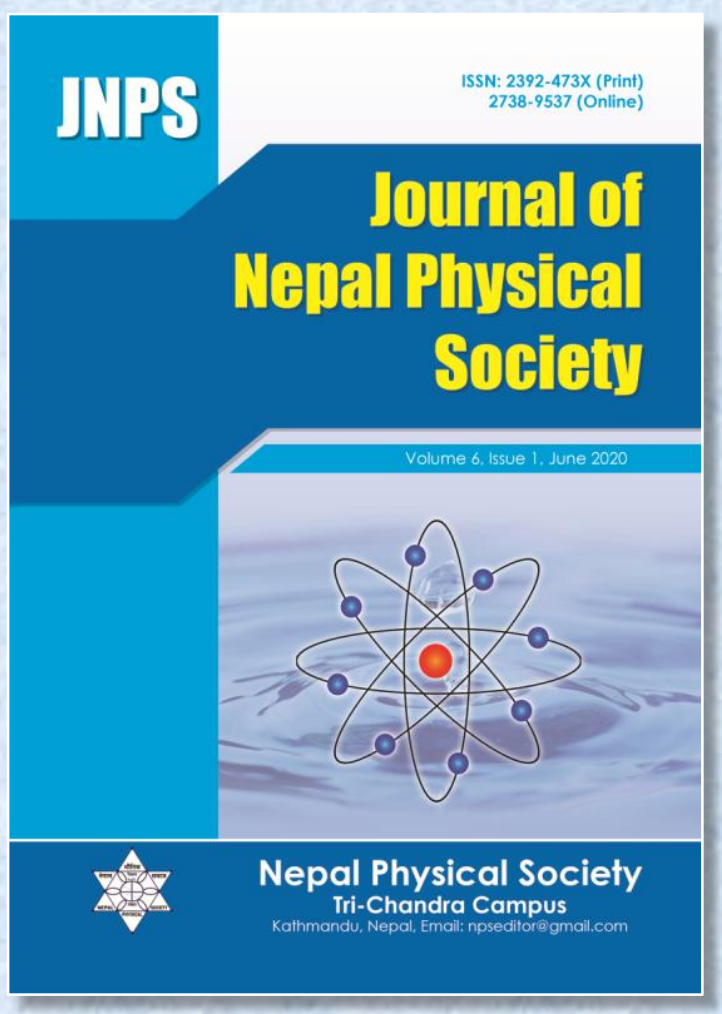

JNPS, 6 (1), 105-112 (2020)

DOI: http://doi.org/10.3126/jnphyssoc.v6i1.30558

Published by:

Nepal Physical Society

P.O. Box: 2934

Tri-Chandra Campus

Kathmandu, Nepal

Email: npseditor@gmail.com 


\title{
Variation on Atmospheric Transmittance Solar Radiation at Kathmandu Valley
}

\author{
P. M. Shrestha ${ }^{1,2,}$, N. P. Chapagain ${ }^{2}$, I. B. Karki ${ }^{3}$ and K. N. Poudyal ${ }^{4}$ \\ ${ }^{1}$ Department of Physics, Patan Multiple Campus, IoST, T. U. \\ ${ }^{2}$ Department of Physics, Amrit Campus, IoST, T.U. Nepal \\ ${ }^{3}$ Nepal Open University, Nepal \\ ${ }^{4}$ Department of Applied Sciences and Chemical Engineering, Pulchowk, Campus, IoE, T. U. \\ "Corresponding Email: prakash.shrestha@ pmc.tu.edu.np
}

Received: 15 Apr., 2020; Revised: 30 May, 2020; Accepted: 25 Jun., 2020

\begin{abstract}
The daily solar irradiance was measured using CMP6 first class pyranometer at the horizontal surface of Kathmandu Valley (Lat::-27.7 $7^{\circ}$, Long.:-85.5 E, Alt. $1350 \mathrm{~m}$ above sea level.) from January to December, 2012 (one year). Monthly mean of atmospheric transmittance is calculated based on different meteorological parameters. The effect of different meteorological parameters as well as physical parameters on the atmospheric transmittance of solar radiation was analyzed. The maximum and the minimum monthly mean solar radiation are found to be $21.32 \pm 4.14 \mathrm{MJ} / \mathrm{m}^{2} /$ day and $10.93 \pm 2.03 \mathrm{MJ} / \mathrm{m}^{2} /$ day in May and January, respectively. The value of yearly mean solar radiation measures is $16.68 \pm 4.60 \mathrm{MJ} / \mathrm{m}^{2} /$ day. Similarly, the annual average of atmospheric transmittance value of $0.51 \pm 0.12$ was obtained that was due to cloudy and more precipitation day during the months of measurements taken. The yearly mean of atmospheric transmittance $0.983,0.987,0.698$ and 0.889 are found due to Rayleigh scattering followed by ozone, water vapor, gas mixture and aerosols respectively, the maximum atmospheric transmittance due to water vapor and while minimum due to gas mixture. This research work will be beneficial for the further identification of other affecting factors of different parameters for the interaction with radiation at different places of the country.
\end{abstract}

Keywords: Air mass, atmospheric transmittance, global solar radiation, meteorological parameters, ozone.

\section{INTRODUCTION}

The main sources of all kind of energies is the Sun. Nuclear fusion reaction is main source of energy od Sun. Four hydrogen atoms combine to form helium atom with liberation of huge amount $26.7 \mathrm{MeV}$ energy. The $6.2 \times 10^{11} \mathrm{~kg}$ of hydrogen mass converts into helium every second. Sun radiates $4 \times 10^{23} \mathrm{~kJ}$ energy in one second [1]. Sun emits electromagnetic wave of wavelength from $300 \mathrm{~nm}$ to $3000 \mathrm{~mm}$. Sun is the closest star of the Earth and hence solar energy is the fundamental as well as primary source of energy which effects Earth's climate and atmosphere. Solar energy has been identified as the largest renewable resources on earth. It is free, clean energy which does not harm to the environment. The solar radiation is used in study of agriculture, hydrology, and climate change. It depends on physical parameters (attitude, longitude, optical air mass, aerosols, cloud, ozone and albedo) and meteorological parameters (precipitation, ambient temperature, wind speed, humidity, local weather conditions and seasonal variation) [2].

The solar radiation incident depends on the geographical location and atmospheric environments. Nepal is land-locked mountainous country in South Asia with a large area of beautiful landscape. Within this small and beautiful setting, it possesses diversity in biosphere and variation of climate. Nepal lies in solar belt (latitude $15^{\circ}$ to $35^{\circ}$ ) in a global map [3]. Annual solar isolation and sunny days are 3.6 to $6.2 \mathrm{kWh} / \mathrm{m}^{2} /$ day and 300 in a year respectively [4].

Kathmandu Valley (Lat.27. $7^{\circ} \mathrm{N}$, long. $85.5^{\circ}$ E, Alt. $1350 \mathrm{~m}$ above sea level) is bowl shaped. It is surrounded by five main mountain ranges Shivpuri (Alt. 2,732 m), Phulchowki (2,742 m), Nagarkot (Alt. $2000 \mathrm{~m})$, Nagarjun Hill $(2,095 \mathrm{~m})$ and Chandragiri $(2,551 \mathrm{~m})$ laying north, south, east, north south and west direction respectively. It is 
capital city of Nepal. It covers about area $893 \mathrm{~km}^{2}$. Its population and population density are $2,510,788$ and $2793 \mathrm{~km}^{-2}$ respectively in 2011[5]. The map of Kathmandu valley is shown in Fig.1.

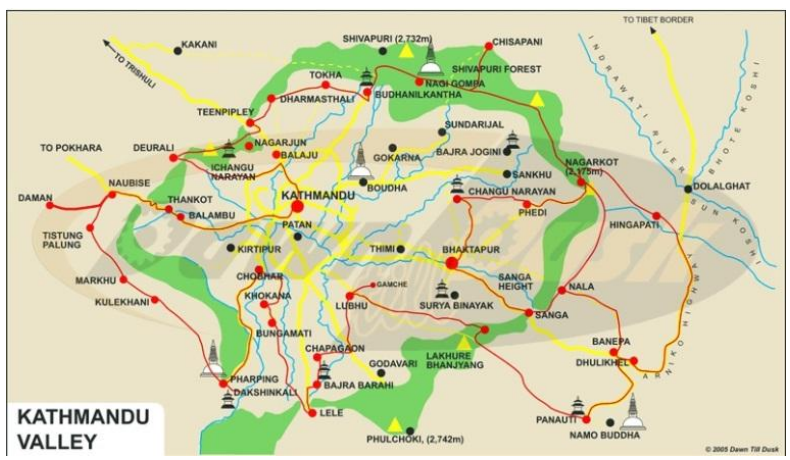

Fig. 1: Map of Kathmandu Valley [source: www.lahistoriaconmapas.com/atlas]

The previous study reported the maximum and minimum global solar radiation (GSR) over Kathmandu are $25.3 \mathrm{MJ} / \mathrm{m}^{2} /$ day and 14.6 $\mathrm{MJ} / \mathrm{m}^{2} /$ day in May and January respectively. The annual average solar energy found to be measuring $5.19 \mathrm{kWh} / \mathrm{m}^{2} /$ day from 2009 to 2010 [6]. Similarly, the average values of attenuation coefficient in Kathmandu during the pre-monsoon period of 1999 are found to be $0.6027 \pm 0.022$ [7]. This study focuses on variation of atmospheric transmittance on solar radiation in Kathmandu Valley using the daily solar irradiance data measured by CMP6 first class pyranometer for one-year 2012.

\section{METHODOLOGY}

The extraterrestrial solar radiation on a horizontal surface $\left(\mathrm{H}_{\mathrm{o}}\right)$ is a function of latitude, hour angle, declination and independent of other location parameters. As the solar radiation passes through the earth's atmosphere to ground, then scattering, reflection, and absorption phenomena takes place by the atmospheric constituents like gas molecules, aerosols, water vapor, ozone and clouds. All the above factors mostly reduce the energy density of solar radiation reaching the surface of the earth. Hence, global solar radiation (GSR) incident on a horizontal surface $\mathrm{H}_{\mathrm{g}}$ is very much location-specific and less than the extraterrestrial radiation. It is affected by physical and meteorological parameters within the top surface of atmosphere to the ground surface of the earth.

By Lambert's law [8]

$$
H_{g}=\tau H_{o}
$$

Where,

$$
\begin{aligned}
& H_{o}=\frac{24}{\pi} I_{S C}\left[1+0.033 \cos \left(\frac{360}{365} n_{d}\right)\right] \\
& \left(\omega_{s} \sin \delta \sin \phi+\cos \delta \cos \phi \sin \omega_{s}\right) \\
& \delta=\text { solar declination }=23.45 \sin \left(\frac{360}{365}\left(284+n_{d}\right)\right) \\
& \mathrm{I}_{\mathrm{sc}}=\text { solar constant }=1367 \mathrm{~W} / \mathrm{m}^{2}[9] \\
& \mathrm{n}_{\mathrm{d}}=\text { no. of day of year (DOY) } \\
& \phi=\text { latitude } \\
& \omega_{\mathrm{s}}=\text { sunshine hour angle }=\cos ^{-1}(-\tan \delta \tan \phi) \\
& \mathrm{N}=\text { length of day }=2 \omega_{\mathrm{s}} / 15 \\
& \mathrm{n}=\text { sunshine hour } \\
& \tau=\text { atmospheric transmittance }
\end{aligned}
$$

Atmospheric transmittance $(\tau)$ depends on atmospheric transmittance due to ozone $\left(\tau_{\mathrm{oz}}\right)$, water vapor $\left(\tau_{\mathrm{w}}\right)$, gas mixture $\left(\tau_{\mathrm{g}}\right)$, aerosol $\left(\tau_{\mathrm{a}}\right)$ and Rayleigh scattering $\left(\tau_{\mathrm{r}}\right)[10,11]$. Atmospheric transmittance due to ozone $\left(\tau_{\mathrm{oz}}\right)$ depend on ozone column(l) and relative air mass $\left(\mathrm{m}_{\mathrm{r}}\right)$. Relative air mass depends on zenith angle $\left(\theta_{\mathrm{z}}\right)$. Atmospheric transmittance due to Water vapor $\left(\tau_{\mathrm{w}}\right)$ depends on water content $(\mathrm{w})$ and relative air $\operatorname{mass}\left(\mathrm{m}_{\mathrm{r}}\right)$. Water content(w) relates relative humidity (RH) and air temperature (T). Similarly, atmospheric transmittance due to gas $\operatorname{mixture}\left(\tau_{\mathrm{g}}\right)$ and Rayleigh scattering $\left(\tau_{\mathrm{r}}\right)$ depend on air mass $\left(\mathrm{m}_{\mathrm{a}}\right)$ which depends on atmospheric pressure $(\mathrm{P})$, altitude and relative air mass. Atmospheric transmittance due to aerosol $\left(\tau_{\mathrm{a}}\right)$ depends on Angstrom coefficient of turbidity $(\beta)$, Angstrom exponential $(\alpha)$ and air mass $\left(m_{a}\right)$.

where,

$$
\tau=0.9751 \tau_{o z} \tau_{w} \tau_{g} \tau_{a} \tau_{r}
$$

$$
\begin{aligned}
& \tau_{o z}=1-\left[0.1611 u_{3}\left(1+139.48 u_{3}\right)^{-0.3035}-0.002715 u_{3}\left(1+0.044 u_{3}+0.0003 u_{3}^{2}\right)^{-1}\right] \\
& \tau_{w}=1-2.4959 w m_{r}\left[\left(1+79.034 w m_{r}\right)^{0.682}+6.385 w m_{r}\right]^{-1} \\
& \tau_{g}=e^{-0.0127 m_{a}^{0.26}} \\
& \tau_{a}=(0.1244 \alpha-0.0162)+(1.003-0.125 \alpha) e^{-\beta m_{a}(1.089 \alpha+0.5123)} \\
& \tau_{r}=e^{-0.0903 m_{a}^{0.83}\left(1.01+m_{a}-m_{a}^{1.01}\right)}
\end{aligned}
$$




$$
\begin{aligned}
& u_{3}=l m_{r} \\
& m_{a}=\frac{P}{101325} m_{r} \\
& m_{r}=\frac{1}{\cos \theta_{z}+0.15\left(93.885-\theta_{z}\right)^{-1.253}}
\end{aligned}
$$

GSR and meteorological data of 2012 are collected from Department of Hydrology and Meteorology Government of Nepal. CMP6 first class pyranometer is used to measure GSR. It has thermopile sensor and spectral range is $285 \mathrm{~nm}$ to $2800 \mathrm{~nm}$ [12].Total Ozone Column (TOC) data are collected from web http:/data.ceda.ac.uk/badc/toms/data/omi/.The

Ozone Monitoring Instrument (OMI) is main part of NASA's Total Ozone Mapping Spectrometer (TOMS) instrument. TOMS is a NASA satellite instrument for measuring ozone values in troposphere. Data of clearness index are collected from https://power.larc.nasa.gov/data-accessviewer/.Statistical tool and MATLAB 2015 software are used to analyze the data and mean; standard deviation and correlation coefficient are used as statistical tools.

\section{RESULTS AND DISCUSSION}

Daily, monthly, and seasonal variation of global solar radiation (GSR) are plotted in Fig.2. Fig 2(a) shows that there is strong correlation in between declination angle. GSR is found maximum 26.99 $\mathrm{MJ} / \mathrm{m}^{2} /$ day in $134^{\text {th }}$ day of year and minimum 3.12 $\mathrm{MJ} / \mathrm{m}^{2} /$ day in $262^{\text {th }}$ day of year.

In Fig. 2(b) shows the monthly variation of GSR which illustrates that there is high fluctuation of solar energy in Kathmandu Valley because of change in season and local weather condition. The maximum GSR is $21.32 \pm 4.14 \mathrm{MJ} / \mathrm{m}^{2} /$ day in May and minimum GSR is $10.93 \pm 2.03 \mathrm{MJ} / \mathrm{m}^{2} /$ day in January due do variation of declination angle as well as local weather condition. Variation of GSR is large in August whereas less in December. Vertical line in bar diagram shows standard deviation as error bar. In Fig. 2 ( c) shows seasonal variation of GSR which illustrates the maximum GSR $19.95 \pm 3.91 \mathrm{MJ} / \mathrm{m}^{2} /$ day is found in spring due to higher solar zenith angle, high temperature no more clouds and windy and minimum $13.00 \pm$ $1.96 \mathrm{MJ} / \mathrm{m}^{2} /$ day are found in winter season due to less solar zenith angle, less temperature, more cloudy and haze. GSR varies large in Summer but less in Winter. Here error bar in diagram shows standard deviation.

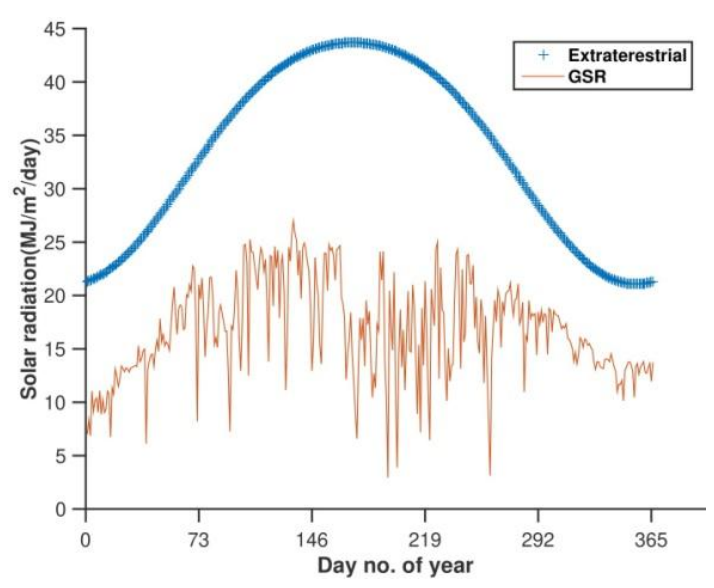

a) Daily variation of extraterrestrial and GSR

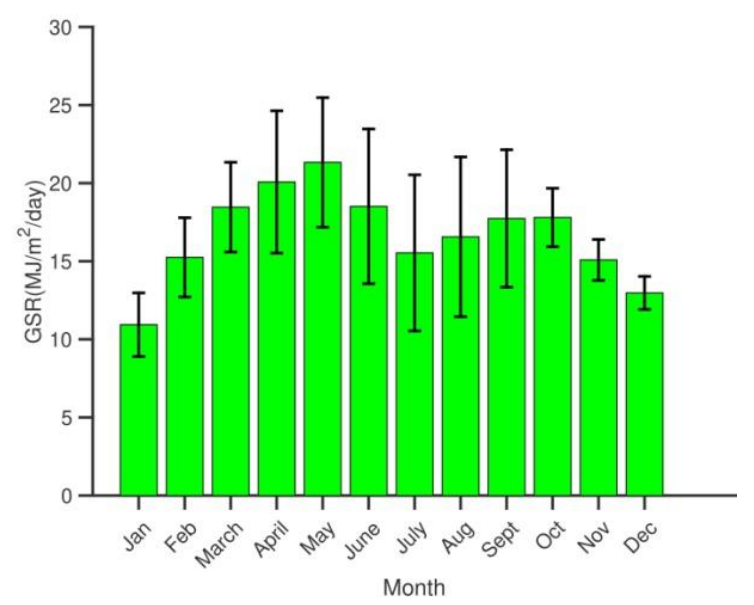

b) Monthly variation of GSR

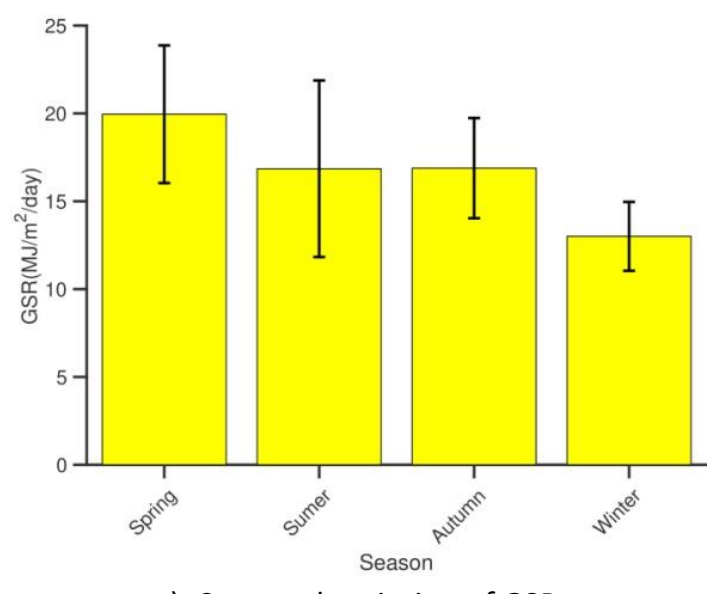

c) Seasonal variation of GSR

Fig. 2: Variation of parameters 
Daily, monthly and seasonal variation of atmospheric transmittance are shown in Fig 3. Atmospheric transmittance is maximum with value of 0.70 and minimum is 0.06 are in March 9 and in July 13 respectively as shown in Fig3(a). In Kathmandu, the number of purely clear sky days $(\tau$ $>0.65)$ is 36 and cloudy day $(\tau<0.34)$ is 41 due to variation of local weather, rainfall and clouds. Fig 3(b) shows monthly variation of atmospheric transmittance. It is maximum $0.63 \pm 0.03$ in November whereas minimum $0.36 \pm 0.11$ in July

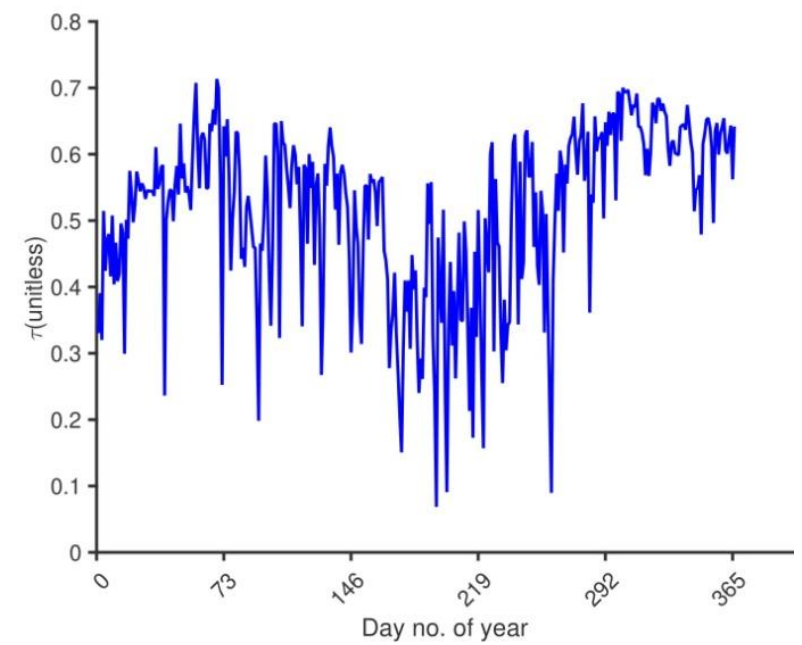

a)Daily variation of transmittance

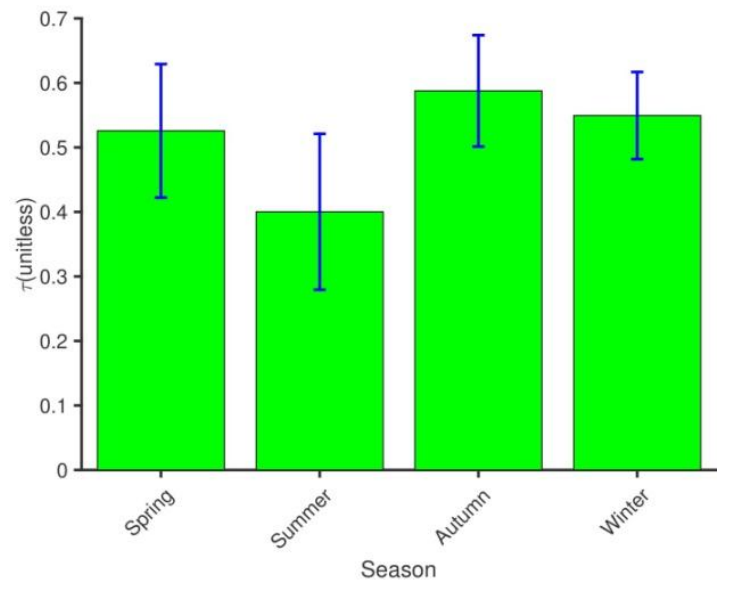

c) Seasonal variation of transmittance due to rainfall. It varies large in August whereas less varies in November.Fig3(c) shows seasonal variation of atmospheric transmittance. Transmittance is maximum $0.58 \pm 0.08$ in Autumn whereas minimum $0.40 \pm 0.12$ in Summer. It varies large in Summer and less in Winter. Fig 3(d) shows variation of clearness index (ratio of extraterrestrial solar radiation to solar isolation) according to satellite data which illustrates that maximum clearness index in March and November whereas minimum in July.

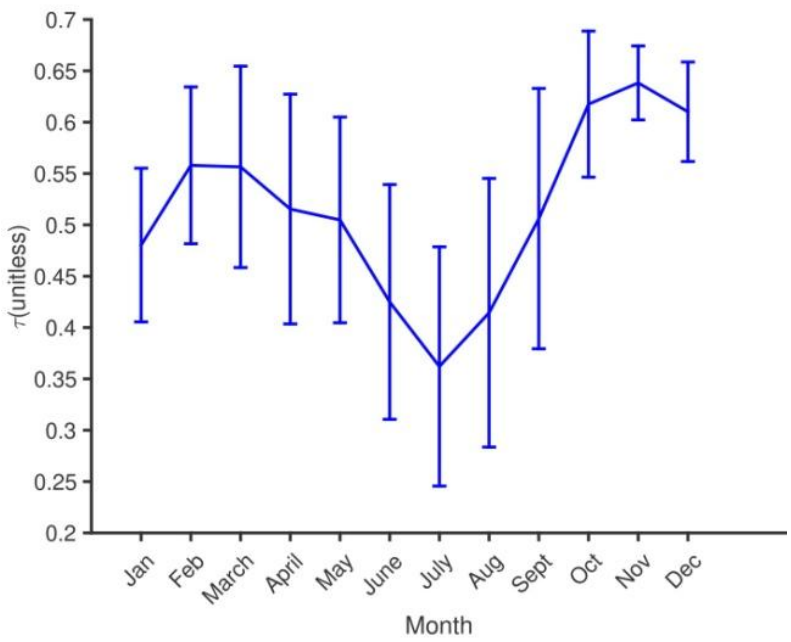

b)Monthly variation of transmittance

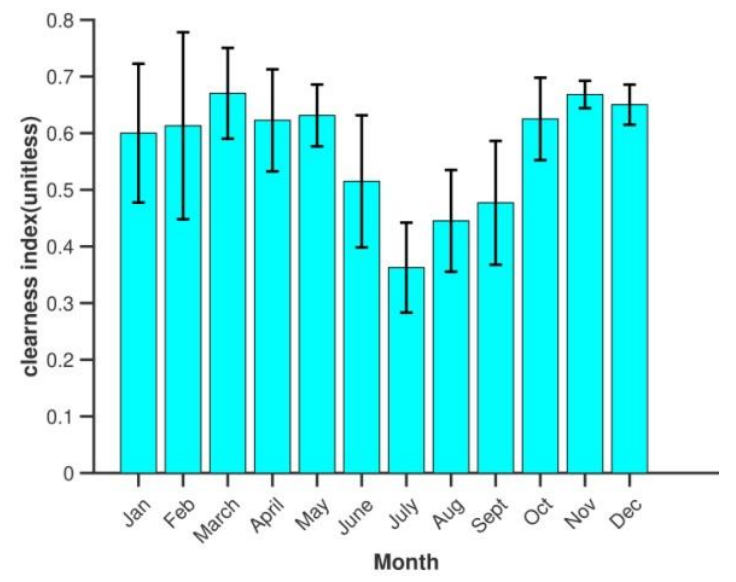

d) Monthly variation of clearness index

Fig. 3: Variation of parameters

Fig. 4(a) shows transmittance due to ozone. It is maximum 0.987 in May whereas minimum 0.978 in December. Fig. 4(b) shows transmittance due to gas mixture. It is maximum 0.987 in June whereas minimum 0.985 in December. Fig. 4(c) shows transmittance due to Rayleigh scattering. It is maximum 0.908 in July whereas minimum 0.855 in
December. Fig.4(d) shows transmittance due to water vapor. It is maximum 0.887 in June whereas minimum 0.871 in December. Fig.4( e) shows transmittance due to aerosol. It is maximum 0.900 in November due to clear sky whereas minimum 0.472 in July due to rainfall. 

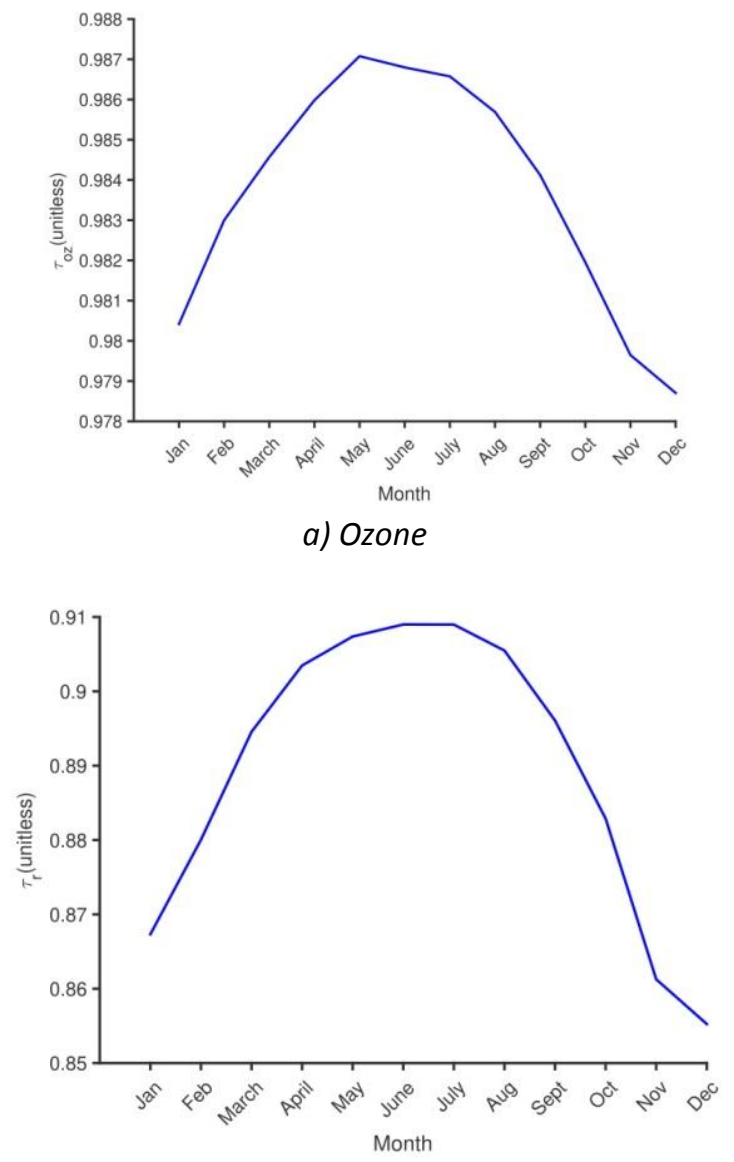

c) Rayleigh

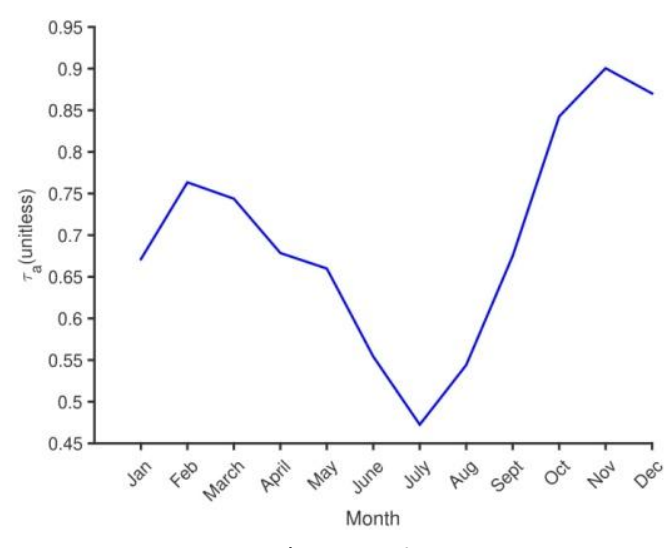

e) Aerosol

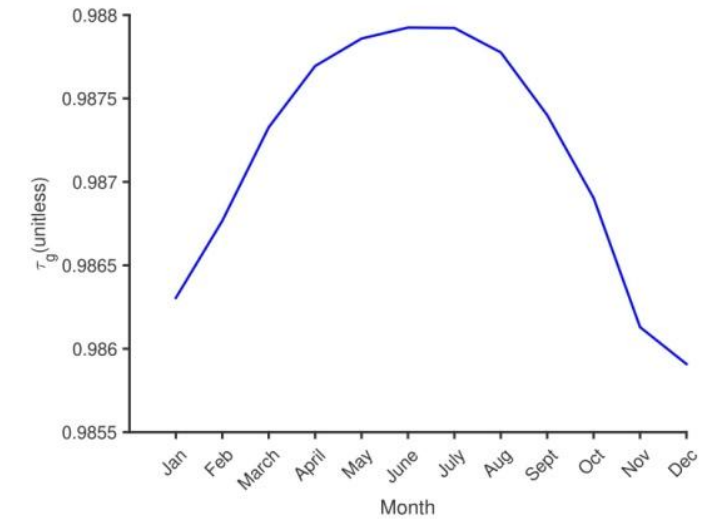

b) Gas mixture

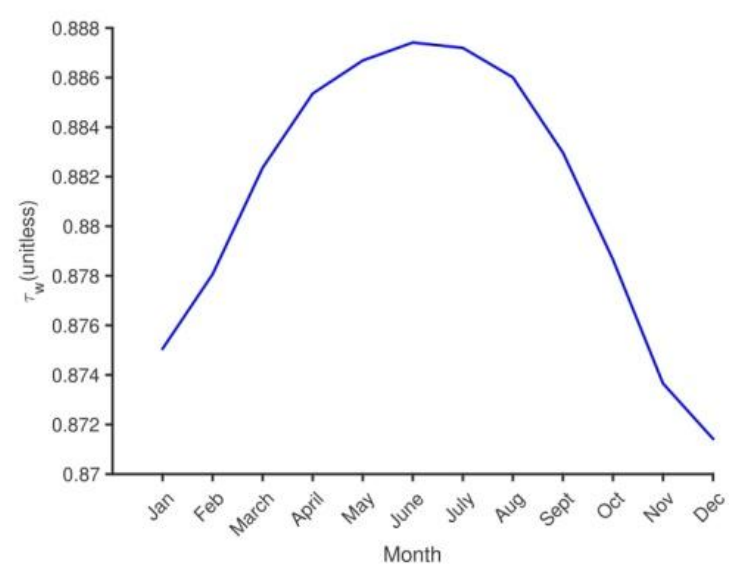

d) Water vapor

Fig. 4: Variation of atmospheric transmittance due to parameters

Temperature of hottest day is $35.2^{\circ} \mathrm{C}$ in June 13 and that of coldest day is $0^{\circ} \mathrm{C}$ in January 14 . Number of rainy days is 121 and total rain fall is $1464.7 \mathrm{~mm}$. Annual mean of maximum and minimum temperature of Kathmandu in 2012 are $26.23 \pm 4.96^{\circ} \mathrm{C}$ and $12.38 \pm 6.83^{\circ} \mathrm{C}$ respectively. Annual mean of relative humidity is $74.87 \pm 12.60$ $\%$. Fig. 5 shows variation of transmittance with maximum temperature, minimum temperature, rainfall, and relative humidity $(\mathrm{RH})$. Value of correlation coefficient of transmittance with those parameters are shown in Table 1. Effect of those parameters on atmospheric transmittance are negative. In Fig.5, the annual mean of relative sunshine hour $(\mathrm{n} / \mathrm{N})$ and air mass $0.57 \pm 0.16$ and $1.54 \pm 0.42$ are found respectively. The annual mean total ozone column (TOC) is $251.02 \pm 4.09$ DU. 

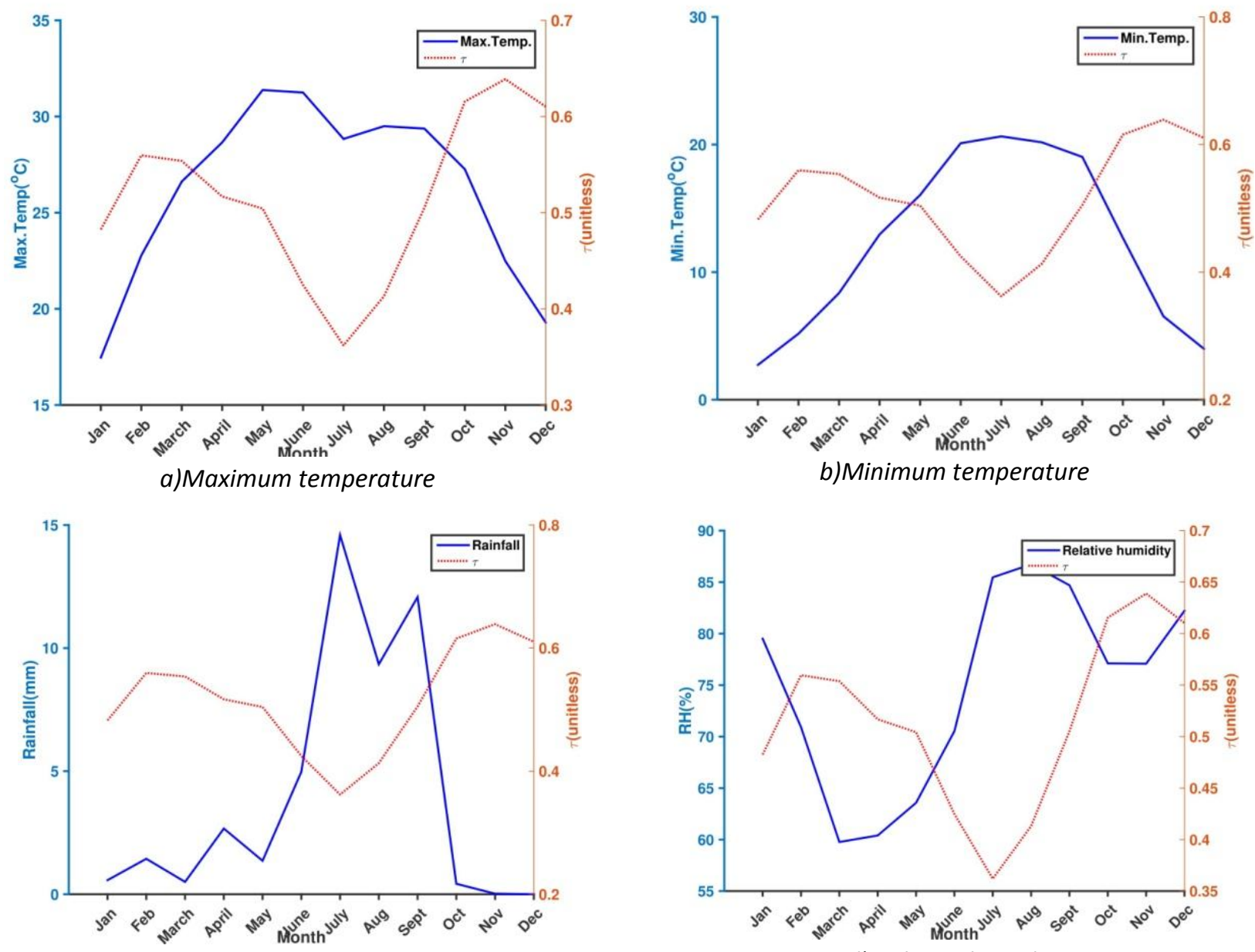

c) Rainfall

d) Relative humidity

Fig.5: Variation of atmospheric transmittance with maximum and minimum temperature, rainfall and relative humidity

Fig. 6 shows variation of transmittance with water content, air mass, relative sunshine hour and TOC. Value of correlation coefficient of transmittance with those parameters are shown in Table 1. Effect

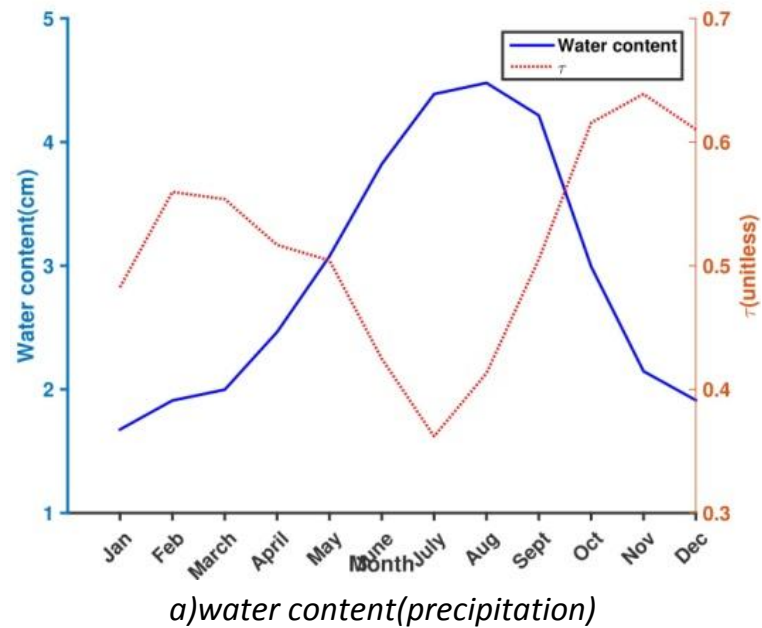

of air mass and relative sunshine hour on transmittance are positive. TOC and water content effect negatively on transmittance.

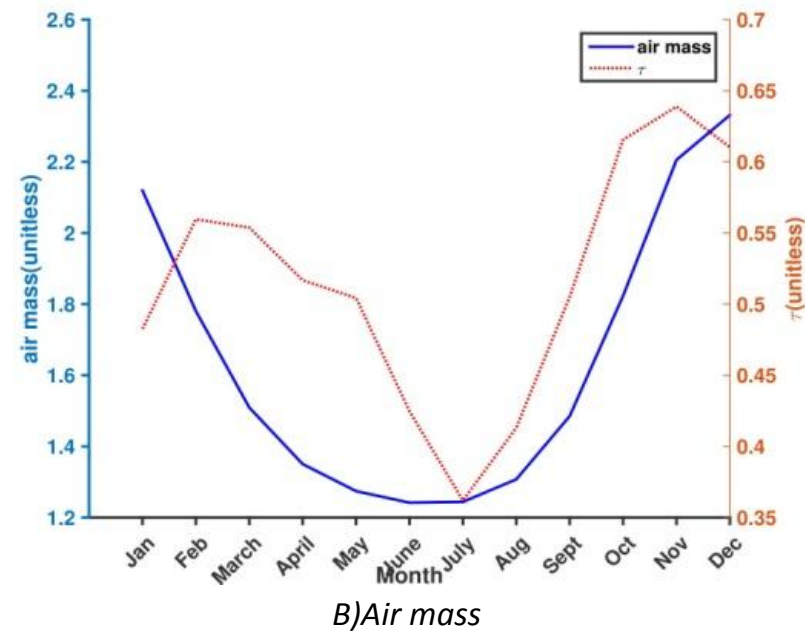




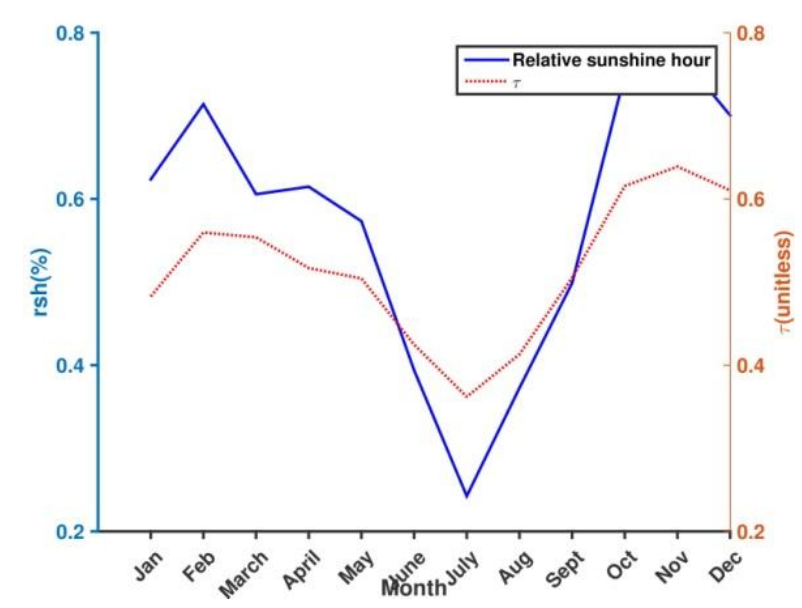

c) Relative sunshine hour

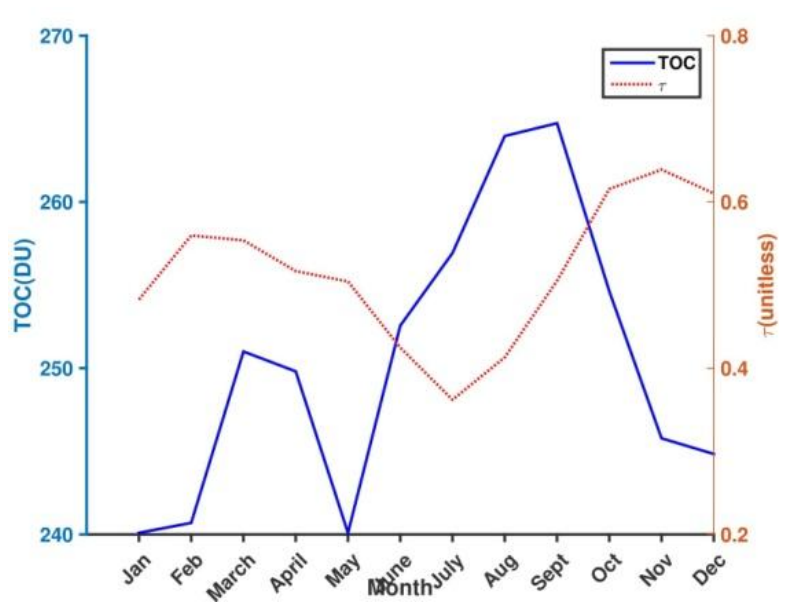

d) Total ozone column

Fig.6: Variation of atmospheric transmittance with water content, air mass, relative sunshine hour and total ozone column

Table 1: Relation of transmittance with meteorological parameters

\begin{tabular}{|l|l|}
\hline Parameters & Correlation coefficient \\
\hline Maximum temperature & -0.48 \\
\hline Minimum temperature & -0.70 \\
\hline Rainfall & -0.75 \\
\hline Relative humidity & -0.23 \\
\hline Water content & -0.70 \\
\hline Air mass & 0.68 \\
\hline Relative sunshine hour & 0.95 \\
\hline Total ozone column & -0.41 \\
\hline
\end{tabular}

\section{CONCLUSION}

The annual mean GSR and atmospheric transmittance values $16.68 \pm 4.60 \mathrm{MJ} / \mathrm{m}^{2} /$ day and $0.51 \pm 0.12$ are found in 2012 at Kathmandu Valley respectively. This result shows that about half of solar radiation is transmitted through atmosphere due to various factors. 5452 TJ solar energy incident in Kathmandu Valley in 2012.Solar energy is pollution free renewable energy. In addition that, there is strong positive and negative correlation is found to atmospheric transmittance with sunshine duration and precipitation respectively because of high value of transmittance is occurred at high sunshine hour. Similarly, lower values of atmospheric transmittance is found at high precipitation. The yearly mean of atmospheric transmittance $0.983,0.987,0.698$ and 0.889 are found due to Rayleigh scattering followed by ozone, water vapor, gas mixture and aerosols respectively. Main obstacle of atmospheric transmittance is aerosols. Aerosols transmit about $68 \%$ solar radiation. Aerosols is due to fuel combustion, vehicle, industry etc.

\section{ACKNOWLEDGMENT}

Authors are grateful to express thank to Department of Hydrology and Meteorology Government of Nepal for providing data for this study. It is highly acknowledged. It is highly acknowledged to Nepal Academy of Science and Technology (NAST) for providing $\mathrm{PhD}$ fellowship to carry out this research project.

\section{REFERENCES}

1. Kamide, Y. and Chian, ACL. Handbook of the Solar-Terrestrial Environment, Springer-Verlag Berlin Heidelberg, German, (2007). 
2. Salby, M. L. Physics of the Atmosphere and Climate. Cambridge University Press, United Kingdom, (2012).

3. Shrestha, J.N., Bajracharya, TR., Shakya, SR., and Giri B. Renewable Energy in Nepal-Progress at a glance from 1998 to 2003, Proceedings of the International Conference on Renewable Energy Technology for rural Development (RETRUD-03) 3, 12-14, (2003)

4. Poudyal, K. N., Bhattarai, B. K., Sapkota,B., and Kjeldstad ,B. Solar radiation potential at four sites of Nepal. Journal of the Institute of Engineering, 8,189- 197 (2011).

5. Sapkota, B. and Dhaubhadel. R. Atmospheric turbidity over Kathmandu Valley, Atmospheric Environment, 36,1249 - 1257 (2002).
6. Iqbal, M. An introduction to solar radiation. Academic Press, United States (1983).

7. Duffie, J. A. and Beckman, WA. Solar engineering of thermal processes. John Wiley \& Sons, Hoboken, New Jersey, United States, (2013).

8. Wang, L., Chen, Y., Niu ,Y., Salazar ,GA., and Gong ,W. Analysis of atmospheric turbidity in clear skies at Wuhan, central China. Journal of Earth Science, 28,729-738 (2017).

9. Adam, M. N. and Nobi, E. F. Correlation between air temperature and Atmospheric turbidity at a Subtropical location. World Environment, 7,1 - 9 (2017). 